\title{
SOLIDARITY TOURISTS: THE IMPACT OF PERCEIVED QUALITY ON SOCIALLY RESPONSIBLE BEHAVIOR
}

\author{
Youssef Makloul $^{1}$, Jaouad Chaabt ${ }^{2}$, Rasa Pranskuniene ${ }^{3}$ \\ ${ }^{1}$ PhD-HDR Professor. Cadi Ayyad UniversityMarrakech ENCG, \\ Phone number+212661352399, E-mail addressy.makloul@uca.ma. \\ 2 PhD student. Cadi Ayyad UniversityMarrakech FSJES, \\ Phone number+212654460473m E-mail address chaabt.jaouad@gmail.com. \\ ${ }^{3}$ Lecturer PhD, Vytautas Magnus University, Lithuania, Lithuania. \\ Phone number+37061518332mE-mail address rasa.pranskuniene@vdu.lt
}

Received 19-08-2019; Accepted 09-03-2020

\begin{abstract}
This research project aims to analyze the impact of perceived quality on the socially responsible behavior of solidarity tourists in the rural municipality of Asni, Morocco. As a result, we carried out a pilot qualitative study based on maintenance guides administered to hotel owners in the rural town of Asni, seeking to collect their opinions on tourist perceptions of the quality of service provided by the contact staff, with the aim of identifying the needs of tourists and their expectations, thus arousing satisfaction, loyalty and possibly their socially responsible behavior. Regarding the verification of our research hypotheses, we carried out a quantitative study based on questionnaires, administered to solidarity tourists, who come as part of a solidarity trip with tour operators, who guarantee respect for the environment of the places visited and which finance development projects for the benefit of the local population. This research brings many answers to questions that have been raised about the concept of perceived quality and socially responsible behavior. The study helped at least to shed light on certain components and dimensions of service and their importance in the perception by the tourist solidarity.

Keywords: Perceived quality; Satisfaction; Socially responsible behavior; Solidarity tourism.
\end{abstract}

\section{Introduction}

Tourism therefore remains an opportunity for many countries because of its ability to provide new sources of income and create jobs. However, various authors have raised the question of the legitimacy of the development of mass tourism (Béji-Bécheur et al., 2006). At the same time, new forms of tourism such as ecotourism, agro-tourism and solidarity tourism have emerged as alternative solutions. Research on responsible tourism has not addressed the social dimension in tourism, as it has focused more on ecological supply (Dolnicar, 2010), so the emergence of socially responsible consumers (Lecompte, Valette-Florence, 2006), socially engaged (Gonzalez et al., 2009) and tourists concerned about sustainability in the broad sense (Lecompte, 2009) as well,few authors have studied the link between perceived quality and responsible behavior of tourists (Lewis et al., 2013). Solidarity tourism thus becomes a shoulder of economic and social development, specifically for rural areas and isolated areas of the country. According to the latest report by (CESE) on the challenges of the rural world has revealed that poverty and exclusion of these areas, conform risk situations with $40 \%$ of the Moroccan population living in rural areas and mountainous areas where the living conditions are extreme, the solidarity tourism is an opening of entry to put in place a development turned towards the human. The purpose of this research paper - to study the variables of perceived quality that explain the variation in responsible consumption solidarity tourists, using the case of hotels in the rural district of Asni, Morocco.

\section{Theoretical review}

In this work we used the conceptual framework of reasoned action theory, planned behavior, and behavioral theory. The theory of reasoned actionexplains behavior through behavioral intents (Fishbein and Ajzen, 1975) and reveals that attitude is the result of beliefs and existing information.Planned behavior allows one to explain, modify and predict the social behavior of individuals from the knowledge of attitude.

Copyright (C) 2020. Published by Vytautas Magnus University. This is an open access article distributed under the terms of the Creative Commons Attribution Non-Commercial 4.0 (CC BY-NC 4.0) license, which permits unrestricted use, distribution, and reproduction in any medium provided the original author and source are credited. The material cannot be used for commercial purposes. 
This requires that behavior be part of the behavioral intent which itself depends on the attitude towards the behavior and the subjective norm (Ajzen, 1991). The theory of planned behavior postulates that social behavior is excellently voluntary (Ajzen, 1980). Before adopting a behavior, the individual takes into account all the information he possesses, he appreciates the consequences and he also examines the involvement of his act. So, social conduct is seen as the result of reasoned, planned and controlled decision-making. In fact, in the theory of planned behavior, the fulfillment or non-fulfillment of a behavior depends not only on the behavioral intent that is the donor of the will to practice or perform a behavior. According to the behaviorist approach, behaviors are derived from learning. Hence the purpose of the behaviorist approach is to modify behaviors to make them more suitable. Many researchers pay more attention to attitudes to explain behavior. Indeed, attitude and behavior are strongly correlated if both have a similar level of specificity (Fishbein, Ajzen, 1975). On the other hand, attitude that is based on beliefs is the result of perception. Fishben (1963) argues, that when two elements are strongly associated, the attitude will engender an evaluation of the attribute that the consumer attributes to it. Fishbein's behaviourist theory is based on the belief-based attitude of perceived probability when there is an association between attitude and attribute. Behavioral theory (Fishben, 1963) is essential in the study of attitudes. The latter (Fishben, 1963) are based on beliefs and all of an individual's intents toward any object are positively correlated with his attitude towards the object which is the tourist service.

Research hypotheses. Based on these contributions, we could present the following assumptions as the hypotheses: H1: Perceived quality positively impacts the attitude of solidarity tourists, H1.1: Perceived quality positively influences attitude in terms of the cognitive dimension of tourists, H1.2: Perceived quality positively influences attitude in terms of the emotional dimension of tourists, H1.3: Perceived quality positively influences the attitude in terms of the conative dimension of tourists, $H 2$ : Satisfaction moderates the relationship between perceived quality and attitude, H2.1: Satisfaction moderates the relationship between perceived quality and cognitive dimension, H2.2: Satisfaction moderates the relationship between perceived quality and affective dimension, $H 2.3$ : Satisfaction moderates the relationship between perceived quality and conative dimension, $H 3$ : The attitude favorably impacts the socially responsible behavior of solidarity tourists, $H 3.1$ : The more the attitude in terms of the cognitive dimension is favorable, the more the client is socially responsible, H3.2: The more the attitude in terms of the affective dimension is favorable, the more the client is socially responsible, H3.3: The more the attitude in terms of the conative dimension is favorable, the more the client is socially responsible.

\section{Theoretical Framing of Conceptual Model Variables}

According to the theory of planned behavior and which justifies the relation between the 2 variables of the hypothesis 3 , the intent to achieve a given behavior is influenced by three factors: a favorable or an unfavorable evaluation of the behavior (the attitude towards the behavior), the perception of the social pressure which incites to realize or not perform the behavior (the subjective norm) and the feeling of self-efficacy in relation to the behavior (the perceived control over the behavior). Together behavioral attitudes, subjective norms, and perceived control over behavior lead to the formation of behavioral intent, and behavior is the observable response to that intent (Ajzen, 2008). Thus, the more favorable the attitude and the subjective norm, and the greater the perceived control, the stronger the intent of a person to carry out the behavior in question. However, in the case of behaviors where the difficulties are beyond our control, it may be useful to consider perceived control as an additional condition that is added to the intent to decide to achieve or, quite often then, decide not to realize the behavior about the work of Woodside et al. (1989), which justifies the relation between the 2 variables of the hypothesis 1 .

For the theoretical framing of hypothesis $\mathrm{H} 2$, the cases of four services from the works of Cronin and Taylor (1992), as well as from Oliver (1980) research "satisfaction is based on the attitude towards the product/service, but without ever again affecting it" are used. In satisfaction, we note the elements related to perceived quality (cognitive judgment) and the elements related to the emotional context in which the consumption of the product/service is inserted (emotional state). Therefore, satisfaction reproduces feelings about the product/service: it is an emotional state limited in time. The attitude towards the product is "updated" after each new experience. 


\section{Methods of research}

The research is based on the positivist paradigm, testing of the preliminary model which concretizes the related hypotheses. On the other hand we seek to know, among the variables mentioned during our review of the literature, which play the most determining role in socially responsible behavior. Our methodology includes the following: measurement of the constructs, presentation of the survey andsampling, data collection.

Exploratory phase (qualitative pilot study).We administered 4 semi-directive face-to-face interview guides with the owners of 4 hotels in the rural district of Asni. This pilot qualitative study that we conducted aims to determine the items of our quantitative study and seeks better understand and extract other research variables. And there is also important to contextualize the knowledge resulting from the review of literature at our research field.

Confirmatory phase (quantitative study). We administered a face-to-face questionnaire with 106 solidarity tourists from 4 hotels in the rural district of Asni. The population is made up of all the solidarity tourists, who come as part of a solidarity trip with Asni Solidaire (an agency that organizes solidarity trips and who finance development projects for the benefit of the local population) in a stay of 15 days scheduled between April and October of each year. So the population is made up of all the tourists, who visited the rural commune of Asni between June 1 and June 20, 2017, which amounts to 630 tourists on average with all the organizing agencies. We took a sample 106 tourists, who come with the travel agency. As sampling, the quota method was used. As this study aims to verify research hypotheses, so we administered the survey to solidarity tourists, who represent the part of a solidarity trip, coming with travel organizers, who ensure the respect for the environment of the visited places and who found development projects for the benefit of the local population.

\section{Main results}

The presentation of the results of the qualitative and quantitative study aimed to study the impact of the perceived quality on the socially responsible behavior of solidarity tourists, case of the rural commune of Asni. In this regard, our goal was to reveal and interpret the results. We began with a qualitative study, later the quantitative analysis was carried out by the administration of a questionnaire among solidarity tourists, who come as part of a solidarity trip with travel organizers, who finance the development of the projects for the benefit of the people. Therefore, we have used SPSS as data processing software to arrive at the results. The analysis of the results is started by the Spearman test, after, Principal Component Analysis was used andfinally the Multiple Regression Analysis was used as the objective of regression, seeking to perform a set of tests, obtaining a reduced model, that facilitates the explanation of our dependent variable.

Results of the exploratory phase. The results of qualitative study, emerged as themes and subthemes: theme ,the service components" describes subthemes ,the site of the hotel",",ambience“, ,,restaurant"), theme ,the dimensions of services“describessubthemes ,tangibility and reliability of service“",reactivity and helpfulness“ and ,empathy“, theme ,socially responsible behavior" describessubthemes ,personal motive and equity“, „social motive (sustainable development)“ and ,environmental reason“.According to our exploratory study, it is certain that the benefits of solidarity tourism far outweigh those of mass tourism.

Solidarity tourism in the rural municipality of Asni takes into consideration all its operations as part of a systemic approach, that consists in respecting the balance of natural resources and the actions of the visitors. According to the hotels, that we are exploring, the pensions operate in accordance with all the concerns in terms of preserving the environment, protecting it and promoting the local economy. It is understandable, that these rural settlements recruit native people and are rooted in some way, but their level of qualification is clearly insufficient to ensure a good perception of the quality of services and possibly a negative influence on socially responsible behavior solidarity tourists.

The different functions require specific know-how and skills to win the admiration and peace of mind of customers, whose satisfaction and perception of quality is the ultimate goal. The training of administrative staff, 
accommodation and catering must allow learning the rules and concepts essential to the performance of their duties, under the responsibility of the parent ministry.

Results of the confirmatory phase, quantitative study. For the test of the hypotheses we proceeded to the test of Spearman, it is the appropriate test, trying to analyze the relation between two qualitative ordinal variables.

Table 2. Hypothesis test*

\begin{tabular}{|l|l|c|c|}
\hline & \multicolumn{1}{|c|}{ Hypothesis } & P & R \\
\hline H1 & Perceived quality positively impacts the attitude of solidarity tourists & 0,003 & 0,784 \\
\hline H1.1 & Perceived quality positively influences attitude in terms of the cognitive dimension of tourists. & 0,873 & 0,024 \\
\hline H1.2 & Perceived quality positively influences attitude in terms of the emotional dimension of tourists. & 0,003 & 0,732 \\
\hline H1.3 & Perceived quality positively influences the attitude in terms of the conative dimension of tourists. & 0,000 & 0,664 \\
\hline H2 & Satisfaction moderates the relationship between perceived quality and attitude. & 0,000 & 0,809 \\
\hline H2.1 & Satisfaction moderates the relationship between perceived quality and cognitive dimension. & 0,645 & 0,045 \\
\hline H2.2 & $\begin{array}{l}\text { Satisfaction moderates the relationship between perceived quality and affective dimension } \\
\text { Relationship between perceived quality and conative dimension. }\end{array}$ & 0,002 & 0,713 \\
\hline H3 & The attitude favorably impacts the socially responsible behavior of solidarity tourists. & 0,000 & 0,823 \\
\hline H3.1 & $\begin{array}{l}\text { The more the attitude in terms of the cognitive dimension is favorable, the more the client is socially } \\
\text { responsible. }\end{array}$ & 0,711 & 0,036 \\
\hline H3.2 & $\begin{array}{l}\text { The more the attitude in terms of the affective dimension is favorable, the more the client is socially } \\
\text { responsible. }\end{array}$ & 0,000 & 0,633 \\
\hline H3.3 & $\begin{array}{l}\text { The more the attitude in terms of the conative dimension is favorable, the more the client is socially } \\
\text { responsible. }\end{array}$ & 0,001 & 0,901 \\
\hline
\end{tabular}

* Correlation is significant at the 0.05 Level (2-Tailed) $\mathrm{P}<0$,05. Source: Our survey using Spss, version 22.0.

According to this bivariate analysis, we can say that the first hypothesis shows, that the perceived quality related to the services of the hotels (of the commune) positively influences the attitude in terms of the attitudinal components apart from the cognitive component. Thus, the more the perceived quality is favorable, the more solidarity-oriented tourists tend to have a favorable attitude, in terms of the affective and conative dimension and not the cognitive dimension, since the attitude towards the product / service is ,up-to-date" after each new experience. As well the first hypothesis shows, that the tourist at the level of the cognitive component has no information on the level of quality of service offered. This lack of information can be justified by the dominance of mass tourism and its marketing and intensive communication policy, while the budget of these hotels doesn't allow to adopt a marketing and communication service. Tourists express their opinion of the degree of satisfaction without making complaints. Today, tourists express their degree of satisfaction on social networks or platforms intended mainly for the opinions of tourists on their stay, these opinions are likely to influence the choice of establishment.

The figure 2 answers to the question: What are the variables of perceived quality that explain the variation in responsible consumption?

Method of the family of data analysis and more generally of multivariate statistics, which consists of transforming linked variables (called ,correlated“ into statistics) into new variables uncorrelated from each other. These new variables are called ,principal components", or main axes. It allows the practitioner to reduce the number of variables and make the information less redundant.

Through the factorial axis we have determined the significant variables in our model through the ACP analysis, we extracted the variables in a way that the exogenous variables can construct a model. 


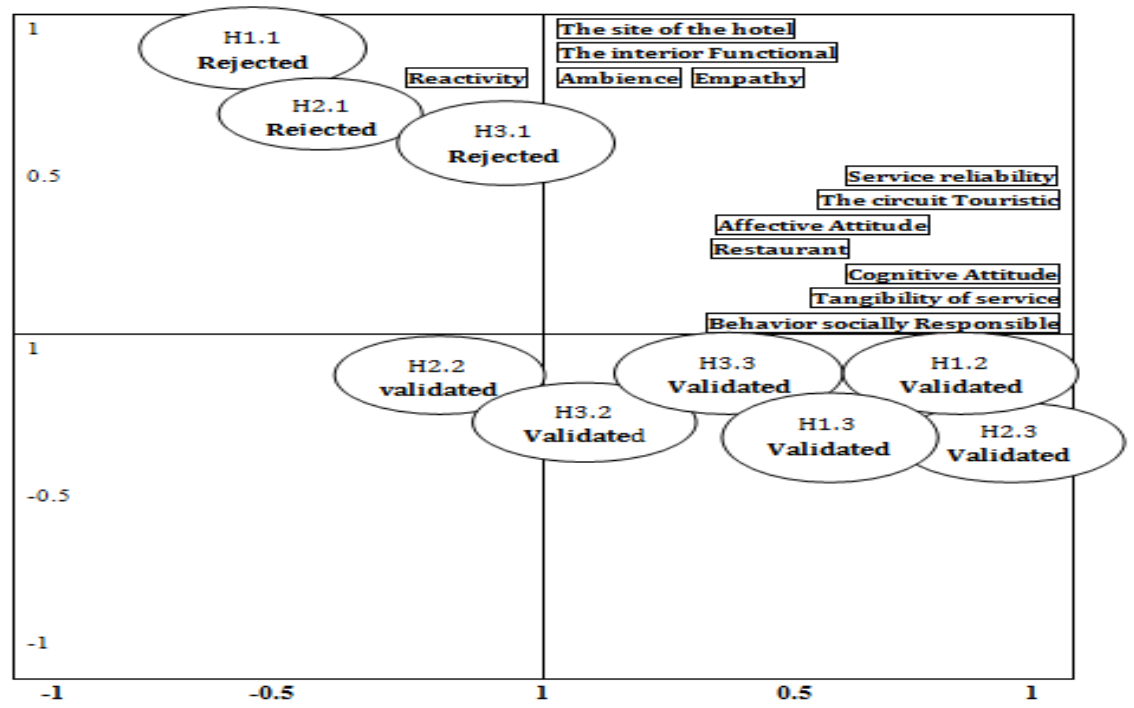

Figure 2. Factorial graph in the factorial space after rotation

According to the factorial axis the first hypothesis that the perceived quality related to the services of the hotels of the commune positively influences the attitude in terms of the attitudinal components apart from the cognitive component, since they are strongly correlated with the axis 2 of the factorial axis. So the more the perceived quality is favorable the more the Solidarity tourists tend to have a favorable attitude in terms of the affective and conative dimension and not the cognitive dimension since the attitude towards the product / service is "updated" after each new experience.

Regarding the second hypothesis. If there is higher perception of quality, so more tourists tend to be satisfied and the study has shown that there is a strong correlation between the two variables since satisfaction is the result from the comparison of the expectations and the perceived quality of the service. Satisfaction comes from the quality of service and not the other way around. This is not because a service is good, that a customer is necessarily satisfied. Satisfaction related to the services of the hotels of the municipality positively influences the attitude in terms of the attitudinal components apart from the cognitive component.

Finally, the third hypothesis, the correlation between the variables, indicates that the attitude in terms of conative and affective component impacts the socially responsible behavior of solidarity tourists. Indeed, we can deduce that the more favorable the attitude and the more the intent of a tourist to achieve the responsible behavior in question is strong.

Multiple regression analysis. The goal of regression is to perform a set of tests to obtain a reduced model that facilitates the application of our dependent variable, these tests are:

Global test: this test is lit differently if our model is accepted globally and the calculation parameters are meaningful or not, at this level on must calculate: R: Correlation coefficient, $\mathrm{R}^{2}$ : Coefficient of determination, Adjusted R2: Adjusted coefficient of determination, Fisher's statistics (F) and its significance.

Table 3. Summary of models

\begin{tabular}{|c|c|c|c|c|}
\hline Model & R & R-two & R-two adjusted & Standard error of estimate \\
\hline 1 & 0,762 & 0,581 & 0,473 & 0,045 \\
\hline \multicolumn{2}{|c|}{$\begin{array}{l}\text { a. Dependent variable: Socially responsible behavior, } \\
\text { b. Predicted values: (constant), attitude: (conative components), The tourist circuit, Indicate your level }\end{array}$} \\
of satisfaction of the whole trip?, How do you evaluate the perceived quality of the services offered by this \\
hotel, Tangible service, attitude: (cognitive components), Restaurant
\end{tabular}

Construct a model that will facilitate the explanation of our endogenous variable. The hypothesis to be tested at this level:H0: the variables selected do not significantly explain our endogenous variable.H1: the variables explain the endogenous variable.Results: The first summary table after data processing on SPSS provides insight 
into the nature of the relationship between the explanatory variables and our dependent variable.R: the correlation coefficient is 0.762 ; this shows that all the variables introduced in our model are strongly correlated in the positive sense with our endogenous variable which is the socially responsible behavior. $\mathrm{R}^{2}$ : Coefficient of determination is 0.580 ; which proves that the exogenous variables in our model explain up to $58 \%$ of our endogenous variable. At this level, we can see that the residual variables represent only $42 \%$ in our model. We also note that $\mathrm{R}^{2}$ is much higher than $\mathrm{R}^{2}$ adjusted which proves that our model is accepted, but we just have to eliminate some variables that are not significant. Also adjusted $\mathrm{R}^{2}$ allows us to conclude that only $47.3 \%$ of the introduced variables that are significant while the others can't correctly explain our model. After having found that our model is accepted globally, we must check if the parameters ( $R ; R^{2} ; R^{2}$ adjusted) obtained in the summary table are significant, that is, they respect the confidence interval determined upstream (90\%). Processing at this level is done using the ANOVA chart and Fisher's Test to determine whether these parameters are representative or not.

Table 4. Table ANOVA

\begin{tabular}{|r|c|c|c|c|c|}
\hline Modèl & Sum of squares & Ddl & Average squares & D & Sig. \\
\hline $1 \quad$ Regression & 16,671 & 7 & 2,382 & 0,813 & $0,004 \mathrm{~b}$ \\
Résidual & 287,102 & 98 & 2,930 & & \\
Total & 303,774 & 105 & & \\
\hline \multicolumn{6}{|r|}{ a. Dependent variable: Socially responsible behavior. } \\
b. Predicted values: (constant), attitude: (conative components), The tourist circuit, Indicate your level of \\
satisfaction of the whole trip?, How do you evaluate the perceived quality of the services offered by this hotel, Tangible \\
service, attitude: (cognitive components), Restaurant
\end{tabular}

In the table, we see that $\mathrm{F}$ read $=7.51$, then $\mathrm{F}$ cal $(=8.88)$ is greater than $\mathrm{F}$ read from the table, so we reject the null hypothesis and we accept $\mathrm{H} 1$ which states that the parameters are significant. So from the analysis of the two tables, we can see that our model is acceptable at the global level, that is to say, the independent variables introduced manage to explain our variable, which is the socially responsible consumption of solidarity tourists. Particular test. In this case we will try to analyze the variables to determine which ones are significant and which ones are not. We will perform an analysis of each variable using the table of coefficients while comparing „T cal" in the table and „T read" from the table of the normal law. This test uses the Student's law, but because all the laws converge to the normal law, so the value of $\mathrm{T}$ will be read from the reduced normal centered law.

Table 5. Table of coefficients.

\begin{tabular}{|c|c|c|c|c|c|}
\hline \multirow{2}{*}{ Model } & \multicolumn{2}{|c|}{ Unstandardized coefficients } & \multirow{2}{*}{$\begin{array}{c}\text { Standardized } \\
\text { coefficients }\end{array}$} & \multirow{2}{*}{$\mathrm{T}$} & \multirow{2}{*}{ Sig. } \\
\hline & $\mathrm{A}$ & Standard error & & & \\
\hline \multirow{14}{*}{$\begin{array}{l}\text { (Constant) } \\
\text { Atmosphere } \\
\text { The site of the hotel } \\
\text { Functional interior } \\
\text { Attitude: (conative components) } \\
\text { attitude: (affective components) } \\
\text { attitude: (cognitive components) } \\
\text { Empathy } \\
\text { Reactivity and helpfulness } \\
\text { Service reliability } \\
\text { Tangibility of service } \\
\text { Restoration } \\
\text { Indicate your level of satisfaction with the quality } \\
\text { of service as a whole. } \\
\text { Tourist circuit }\end{array}$} & 0,837 & 0,251 & & 3,340 & 0,001 \\
\hline & 0,216 & 0,027 & 0,091 & 0,786 & 0,435 \\
\hline & 0,753 & 0,049 & 0,185 & 1,534 & 0,130 \\
\hline & 0,010 & 0,032 & 0,039 & 0,314 & 0,755 \\
\hline & 0,155 & 0,035 & 0,050 & 2,422 & 0,047 \\
\hline & 0,424 & 0,030 & 0,165 & 3,410 & 0,016 \\
\hline & 0,021 & 0,034 & 0,072 & 0,608 & 0,545 \\
\hline & 0,143 & 0,029 & 0,055 & 0,469 & 0,641 \\
\hline & $-0,403$ & 0,033 & $-0,148$ & $-1,228$ & 0,224 \\
\hline & 0,432 & 0,026 & 0,17 & 2,399 & 0,021 \\
\hline & 0,521 & 0,032 & 0,165 & 2,829 & 0,022 \\
\hline & 0,291 & 0,024 & 0,145 & 2,482 & 0,062 \\
\hline & 0,780 & 0,011 & 0,214 & 3,318 & 0,021 \\
\hline & 0,730 & 0,011 & 0,214 & 3,318 & 0,021 \\
\hline
\end{tabular}


a. Dependent variable: Socially responsible behavior,

b. Values predicted: Atmosphere, Hotel site, Functional interior, attitude: (conative components), attitude: (affective components), attitude: (cognitive components), Empathy, Reactivity and helpfulness, Reliability of service, Tangible service, Restaurant, Indicate your level of satisfaction with the quality of service as a whole.

The value of T read is 1.65. So it is now a question of comparing „,T cal“ in the table with „T read" of the table for the set of variables. For the ambience variable We note that $\mathrm{T}$ cal $=0.786(<1.65)$, For the variable site of the hotel We note that $\mathrm{T}$ cal $=1.534(<1.65)$, For the interior functional variable We note that $\mathrm{T}$ cal $=0.314(<1.65)$, For the cognitive variable We note that $\mathrm{T}$ cal $=0.608(<1.65)$, For the variable empathy We note that $\mathrm{T}$ cal $=0.469(<1.65)$, For the variable responsiveness and helpfulness? Note that $\mathrm{T}$ cal $=-1.228(<1.65)$. The set of these variables are insignificant variables while $\mathrm{T}$ Cal $<\mathrm{T}$ read, while for the other variables we notice that $\mathrm{T}$ cal is greater than the value of $\mathrm{T}$ read from the table, so the rest of the exogenous variables are significant.

$$
\text { Reduced Model: } \mathrm{Y}=0,837+0,78 \mathrm{X} 1-0,73 \text { X2 +0,521 X3 + 0,432X4 + 0,424X5 + 0,291 X6 + 0,155X7 }
$$

Here: X1. Satisfaction; X2. Tourist tour; X3. Tangibility of service; X4. Service reliability; X5. The attitude: (affective components); X6. Restauration; X7. The attitude: (conative components).

After determining the significant variables in our model, we need to extract the variables in a way that the exogenous variables can build a model that facilitates the explanation and interpretation of our starting variable impact of perceived quality on the socially responsible behavior of solidarity tourists.

\section{Limitations of this study}

Several points limit the results of our study. Firstly, for sampling, the sample size is not large and the characteristics of our sample may restrict the representativeness of the sample in relation to the total population. It then constitutes a limitation to the generalization of results on the Total population.

The major limitation of the pilot qualitative study lies in the fact that we haven't been able to identify a work done in the Moroccan context and concerning socially responsible behavior in order to be able to retain the most significant and appropriate attributes to our context, so we have chosen to carry out a complementary exploration aiming at first to contextualize the knowledge (the knowledge exists in itself which justified the choice of our positivist paradigm) and to explore other variables of research.

\section{Discussion}

In this work we have tried to measure the impact of quality on the socially responsible behavior of solidarity tourists and to understand how perceived quality can be a determining variable of socially responsible behavior across the dimensions of attitude. We began with the pilot qualitative study, the goal in this study was to determineandbetter understand the items of our quantitative study and, as well as extract other research variables. The purpose of the survey was to provide assistance to the poor, and to cope with social and economic inclusion, the purpose of this survey was to understand the impact of the effects of mediation relationship between perceived quality and socially responsible behavior. So, through the results of the study, we found, that the conative component and the emotional component play a very important and determining role in the attitude of tourists while the cognitive component is not at all an effective determinant. Considering satisfaction as a moderating variable between perceived quality and attitude, we have found that it moderates the relationship between perceived quality and the affective and conative components in order to positively influence the attitude of tourists, while it does not moderate the relationship between perceived quality and the cognitive component in order to favorably influence the attitude of tourists. As for socially responsible behavior, we also noticed that when the client is satisfied and has a favorable attitude, in terms of a conative component and affective component, he is automatically socially responsible, according to the commitment approach. Although the cognitive component has no impact on socially responsible behavior. We hope that these results will help the hotels to increase the socially responsible behavior of its solidarity tourists.

In multidimensional analysis we have determined the significant variables of our conceptual model through the multiple regression analysis. We extracted the variables in a way that the exogenous variables can build a model, that facilitates the explanation and the interpretation of our starting variable the impact of perceived 
quality on the socially responsible behavior of solidarity tourists The variables of our endogenous variable are posed according to the following order of priority: Satisfaction, Tourist itinerary, Tangibility of service, Reliability of service, Attitude (conative components), Attitude (affective components), Restoration.

Concluding our study focused on different dimensions and service components it is important identify the determinants of perceived service quality and socially responsible behavior. Thus, the results of the study showed significant variables in terms of impact on socially responsible behavior. This research provides many answers to the questions that have been asked about the concept of perceived quality and responsible consumption. The study shed light on certain aspects of the service and its perception by the client through the different components and dimensions, in order to identify the attributes determining the quality of service and perceived satisfaction. Thus, the results of the study showed that conative and affective factors are significant variables in terms of impact on socially responsible behavior. Much emphasis is placed on the preponderant role played by the attitude in judging the superiority or inferiority of the service, but possibly in the socially responsible behavior of the solidarity tourists, the meeting of service and in the improvement of the quality service (Bitne, Hubbert, 1994). Hence the quality of service is essential to meet the requirements of customers in a service relationship. In the end, perceived quality becomes a strategicdevelopmentleverforsolidaritytourismestablishments.

\section{Conclusions}

The conclusions we have drawn from the test of each hypothesis.

The first hypothesis shows, the perceived quality related to the services of the hotels of the municipality positively influences the attitude in terms of the attitudinal components apart from the cognitive component. Thus, the more the perceived quality is favorable, the more solidarity-oriented tourists tend to have a favorable attitude in terms of the affective and conative dimension and not the cognitive dimension since the attitude towards the product/service is ,up-to-date“" after each new experience.

The second hypothesis presents: if there is the higher the perception of quality, so moretourists tend to be satisfied and there is a strong correlation between the two variables since satisfaction is the result of comparing quality and quality perceived service. Satisfaction comes from the quality of service and not the other way around. Satisfaction related to the services of the hotels of the municipality positively influences the attitude in terms of the attitudinal components apart from the cognitive component.

The third hypothesis shows the correlation between the variables, indicates that the attitude in terms of conative and affective component impacts the socially responsible behavior of solidarity tourists. Indeed, we can deduce that the more favorable the attitude, the more the intent of a tourist to achieve the responsible behavior in question is strong. Also, when the situation arises, one can expect the person to perform the behavior. The intent thus appears to be the element that directly precedes the behavior.

We present these research perspectives: complementing our model proposal with an exploratory qualitative study with a fairly large sample in our case we have limited ourselves to a sample of 4 hotels, in combination with the questionnaire. We identified the main factors used by the client to evaluate the perceived quality of the service (during their service experience). Some criteria had already been identified in the literature and others emerged from the results. We suggest incorporating into our perception model, other relevant variables that relate to the service attitudes of the staff in contact, examples: personalization, loyalty and perfomance, these variables are likely to lead to more interesting results and allow improve customer perception of service by reducing the gap between the expected service quality and the perceived quality and increase the level of overall tourist satisfaction and possibly its socially responsible behavior.

\section{References}

Ajzen, I. (1991). The theory of planned behavior. Organizational behavior and human decision processes, Vol. 50(2), p. $179-211$.

Ajzen, I., \& Cote, N. G. (2008). Attitudes and the prediction of behavior. Attitudes and attitude change, p. 289-311.

Ajzen, I.et Fishbein, M. (1980). Understanding attitudes and predicting social behavior.

Béji-Bécheur, A., \& Bensebaa, F. (2006). Companies' practices and social responsibility: cases of the French tourist sector.

Bitner, M. J., \& Hubbert, A. R. (1994). Encounter satisfaction versus overall satisfaction versus quality. Service quality: New directions in theory and practice, $\operatorname{Vol} 34(2)$, p. 72-94.

Cronin, Jr, J. J., \& Taylor, S. A. (1992). Measuring service quality: a reexamination and extension// Journal of marketing. Vol. 56(3), p. 55-68. Online access: https://doi.org/10.1177/002224299205600304. 
Dolnicar, S. (2010). Identifying tourists with smaller environmental footprints. Journal of sustainable tourism, Vol. 18(6), p. 717734.

Fishbein, M. (1963). An investigation of the relationships between beliefs about an object and the attitude toward that object. Human relations, Vol. 16(3), p. 233-239. Online access: https://oi.org/10.1177/001872676301600302.

François-Lecompte, A., \& Prim-Allaz, I. (2009). Les Français et le tourisme durable: proposition d'une typologie. Management Avenir, No. 9. p/ 308-326.

Hergli, S., Sahut, J. M., \& Teulon, F. (2012). Politiques et stratégies de développement durable dans le secteur hôtelier: le cas d'ACCOR. // Management Avenir, No. 6, p. 154-168.

Kaiser Fg, Wolfing S, Fuhrer U., 1999, Environmental attitude and ecological behavior. Journal of environmental psychologyVol. 19(1):p. 1-19.

Ko, D. W., \& Stewart, W. P. (2002). A structural equation model of residents' attitudes for tourism development. Tourism management, Vol. 23(5), p. 521-530. Online access: https://doi.org/10.1016/S0261-5177(02)00006-7.

Lecompte, A. F., \& Valette-Florence, P. (2006). Mieux connaître le consommateur socialement responsable. Décisions marketing, p. 67-79. Online access: https://www.jstor.org/stable/40593054.

Lewis, V. A., MacGregor, C. A., Putnam, R. D. (2013). Religion, networks, and neighborliness: The impact of religious social networks on civic engagement // Social Science Research, Vol. 42(2), p. 331-346. Online access: https://doi.org/10.1016/j.ssresearch.2012.09.011

Merasli S. (2004). La qualité dans l'industrie du tourisme // Un impératif majeur pour un tourisme durable, téoros, p. 23-2

Najar, C,Zaiem I., (2010). Influence de l'implication durable sur l'intention et le comportement d'achat écologique. Revue libanaise de gestion et d'économie, Vo. 3(4), p. 1-35.

Office of the High Commissioner for Planning (HCP). Online access: https://www.hcp.ma.

Oliver, R. L. (1980). A cognitive model of the antecedents and consequences of satisfaction decisions// Journal of marketing research,Vol. 17(4), p. 460-469. Online access: https://doi.org/10.1177/002224378001700405.

Rigall I, Torrent R. (2008). Sustainable development in tourism municipalities: The role of public goods //Tourism management 29(5): p. 883-897.

Woodside, A. G., Frey, L. L., Daly, R. T. (1989). Linking sort/ice anlity, customer satisfaction, and behavioral intention // Journal of health care marketing, Vol .9(4), p. 5-17.

Zgolli, S., Zaiem, I. (2018). The responsible behavior of tourist: The role of personnel factors and public power and effect on the choice of destination// Arab Economic and Business Journal, Vol. 13(2), p. 168-17. 